\title{
Antipsychotic Prescribing Patterns in First-episode Schizophrenia: A Five-year Comparison
}

\author{
Daeyoung Roh', Jhin-Goo Chang², Sol Yoon ${ }^{2}$, Chan-Hyung Kim ${ }^{2,3}$ \\ ${ }^{1}$ Department of Psychiatry, Hallym University Chuncheon Sacred Heart Hospital, Hallym University College of Medicine, Chuncheon, \\ ${ }^{2}$ Department of Psychiatry, Severance Hospital, ${ }^{3}$ Institute of Behavioral Science in Medicine, Yonsei University College of Medicine, Seoul, \\ Korea
}

Objective: Early treatment choice is critical in first-episode schizophrenia-spectrum disorders. The purpose of this study was to describe prescribing trends of antipsychotics use in patients with first-episode schizophrenia in 2005 and 2010, respectively. Methods: We reviewed the medical records of newly treated patients with schizophrenia from a university psychiatric hospital in $2005(n=47)$ and 2010 ( $n=52)$. We defined patients as receiving a high antipsychotic dose if their ratio of prescribed daily dose (PDD) to defined daily dose (DDD) was greater than 1.5.

Results: The rates of high-dose antipsychotic prescription were $61.7 \%$ and $53.8 \%$ in 2005 and 2010 , respectively. The rates of antipsychotic polypharmacy were 34.6\% in 2005 and 34.0\% in 2010. The most common first-prescribed antipsychotics were (in descending order of prescription frequency) olanzapine, risperidone, aripiprazole, and haloperidol in 2005 and risperidone, quetiapine, paliperidone, and olanzapine in 2010. High-dose antipsychotics were significantly associated with antipsychotic polypharmacy (odds ratio=23.97; $p<0.01$ ). More individuals were treated with mood stabilizers in 2010 than in 2005 ( $p=0.003$ ). Conclusion: The practice of prescribing high-dose antipsychotics and associated antipsychotic polypharmacy were common even for initial treatment of first-episode schizophrenia in 2005 and 2010. In 2010, the list of the most common first-prescribed antipsychotics changed, and the use of mood stabilizers increased in non-affective schizophrenia

KEY WORDS: Schizophrenia; Antipsychotic agents; Polypharmacy; First-episode; Antimanic agents.

\section{INTRODUCTION}

The onset of schizophrenia illness typically occurs in late adolescence or early adulthood, with patients showing neurodevelopmental alterations as well as a progressive decline in overall functions. ${ }^{1)}$ The deterioration is evident in psychopathological, neurocognitive, and functional areas following the initial onset of a psychotic episode. Lifetime maintenance therapy may improve social functioning and prevent symptom relapse; however, the therapy also causes significant public health problems and economic costs. ${ }^{2)}$ Pharmacological intervention is most efficacious during the first 5 years of illness, ${ }^{3)}$ and the chance of responding to treatment decreases over time.

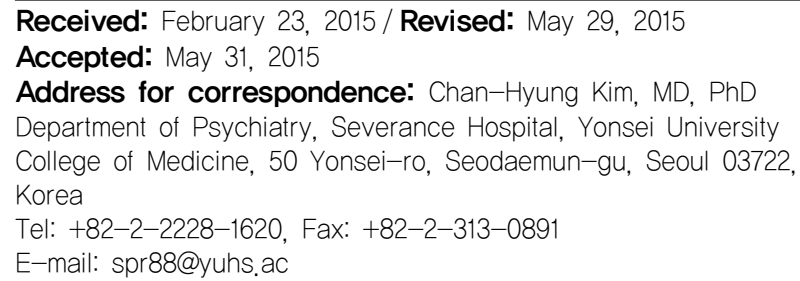

The initial response to medication within the first 1-3 months is highly predictive of long-term disease consequences. ${ }^{5)}$ In this context, the choice of antipsychotic drug is important for first-episode psychosis treatment.

Despite numerous trials investigating first-episode psychosis treatment, no specific drug has been proven to be superior in terms of overall efficacy, with the exception of clozapine in patients with neuroleptic-refractory schizophrenia. ${ }^{6}$ Currently, schizophrenia treatment guidelines recommend second-generation antipsychotics (SGAs) as first-line medications, ${ }^{7-9)}$ as they are associated with fewer extrapyramidal symptoms (EPS) and other favorable side effect profiles. The trend toward more frequent use of SGAs over first-generation antipsychotics (FGAs) from the 1990s to the early 2000s has been reported in many countries. ${ }^{10,11)}$ However, little is known about the more recent changes in the prescription pattern of antipsychotics for first-episode schizophrenia after this shift toward increasing SGA use.

Patients with first-episode schizophrenia are more sensitive to a given dose of antipsychotics than chronic

() This is an Open-Access article distributed under the terms of the Creative Commons Attribution Non-Commercial License (http://creativecommons.org/licenses/by-nc/4.0) which permits unrestricted non-commercial use, distribution, and reproduction in any medium, provided the original work is properly cited. 
patients. ${ }^{12)}$ According to a meta-analysis, ${ }^{13)}$ mean effective doses are up to $50 \%$ lower in first-episode schizophrenia than in chronic schizophrenia. However, it is not uncommon for the patients to be given doses that exceed the recommended therapeutic doses. ${ }^{14,15)}$ Despite consistent recommendations for antipsychotic monotherapy, ${ }^{7,8,12)}$ the practice of prescribing multiple antipsychotic drugs appears to be increasing, ${ }^{11)}$ and an association between antipsychotic polypharmacy and high doses of prescribed antipsychotics has been observed. ${ }^{16,17)}$ Although the use of high-dose prescription and polypharmacy has been studied in chronic patients with schizophrenia, relatively few studies have investigated these treatment strategies in the early stages of the disease.

The present study aimed (1) to examine changes in the prescribing patterns of antipsychotics and other psychotropic drugs between 2005 and 2010, and (2) to identify the relationships among dosage, antipsychotic polypharmacy, and other clinical correlates in patients with first-episode schizophrenia who were discharged from a university psychiatric hospital.

\section{METHODS}

\section{Study Settings}

This study was carried out at Severance Mental Health Hospital, a locked psychiatric inpatient facility located near Seoul and a part of the Unit of Psychiatry in Yonsei University Health System (YUHS). This residency-affiliated facility admits patients transferred from two other YUHS outpatient units in Seoul and several other mental health centers throughout the country, offering short- to medium-term care for patients with acute and subacute psychiatric conditions. This study was approved by the Institutional Review Board of Severance Mental Health Hospital.

\section{Data Source and Study Population}

Data specified according to protocol were collected retrospectively from patient medical records by manual search. Available medical records of all patients with a diagnosis of schizophrenia or schizophreniform disorder (the Diagnostic and Statistical Manual of Mental Disorders 4th edition, text revision [DSM-IV-TR] ${ }^{18)}$ who were discharged from the hospital between January 1, 2005 and December 31, 2010 were analyzed. We excluded data from patients who had a prior history of psychotic episodes before the most recent episode leading to admission. The year 2005 was chosen as most major atypical anti- psychotics (including aripiprazole, which was approved by the Korea Food and Drug Administration [KFDA] for the treatment of schizophrenia in 2004) had become commercialized by 2005 in Korea. The year 2010 was chosen as it was the most recent year from which all medical records were available at the time of investigation.

Patient medical records were checked for disease-specific information (length of stay, voluntary or involuntary treatment) and demographic data (such as sex, age, and socioeconomic status). Comprehensive medication profiles included antipsychotics, mood stabilizers, antidepressants, and benzodiazepines. "As needed" medication prescriptions were excluded from consideration. The prescription status of psychotropic drugs at the time of discharge was chosen for analysis. We defined antipsychotic polypharmacy as the concurrent receipt of two or more chemically distinct antipsychotic drugs for at least 14 days. A wide time window of at least 14 days and the prescription status at the time of discharge (after the patient was mostly stable) were utilized to help reduce overestimation of polypharmacy.

\section{Data Analysis}

To compare doses of different drugs, the prescribed daily dose (PDD) was divided by the defined daily dose (DDD) to yield a PDD/DDD ratio. DDD is the international unit approved by the World Health Organization for drug use studies ${ }^{19)}$ and is defined as "the assumed average maintenance dose per day for a drug used for its main indication in adults." A PDD/DDD ratio was then calculated as the sum of the individual PDD/DDD ratios of all antipsychotics prescribed to each determinate patient. To maintain consistency with previous studies, ${ }^{16,17)}$ a high dose was defined as a PDD/DDD ratio of greater than 1.5.

Continuous variables were analyzed parametrically using $t$-tests. The chi-squared test was used to compare percentages of discrete variables, and Fisher's exact test was used whenever appropriate. Logistic regression analysis was used to adjust for relevant covariates and to identify factors associated with high-dose antipsychotic prescriptions. Initially, potential variables associated with highdose antipsychotic prescriptions (age, sex, length of hospital stay, socioeconomic status, anticholinergics, antidepressants, antipsychotics polypharmacy, benzodiazepines, mood stabilizers, and year of institutionalization) were selected based on the results of prior studies. ${ }^{14,20)}$ After univariate logistic regression, only factors with a significance of $p<0.20$ (age, sex, socioeconomic status, mood stabilizer use, typical antipsychotics use, anti- 
Table 1. Sociodemographic and clinical characteristics of individuals diagnosed with schizophrenia for the first time in 2005 and 2010

\begin{tabular}{|c|c|c|c|c|}
\hline Variable & $2005(n=47)$ & $2010(n=52)$ & $\chi^{2} / t$ & $p$ value \\
\hline Age (yr) & $35.3 \pm 12.6$ & $32.5 \pm 12.9$ & 1.096 & 0.276 \\
\hline \multicolumn{5}{|l|}{ Sex } \\
\hline Male & $15(31.9)$ & $17(32.7)$ & 0.007 & 0.934 \\
\hline Female & $32(68.1)$ & $35(67.3)$ & & \\
\hline Education (yr) & $13.3 \pm 2.4$ & $14.2 \pm 2.5$ & -1.805 & 0.074 \\
\hline \multicolumn{5}{|l|}{ Social economic status } \\
\hline Professional & $0(0)$ & $4(9.3)$ & 6.912 & 0.141 \\
\hline Intermediate & $8(17.0)$ & $6(14.0)$ & & \\
\hline Skilled non-manual/manual & $26(55.3)$ & $27(62.8)$ & & \\
\hline Semi-skilled manual & $10(21.3)$ & $4(9.3)$ & & \\
\hline Unskilled manual & $3(6.4)$ & $2(4.7)$ & & \\
\hline Schizophrenia diagnostic subtype & & & 1.35 & 0.717 \\
\hline Paranoid & $34(72)$ & $38(72.7)$ & & \\
\hline Disorganized & $1(2.1)$ & $2(3.0)$ & & \\
\hline Catatonic & $0(0)$ & $1(1)$ & & \\
\hline Undifferentiated or schizophreniform disorder & $12(25.5)$ & $11(23.2)$ & & \\
\hline Length of hospital stay (day) & $55.6 \pm 55.5$ & $46.1 \pm 27.3$ & 1.088 & 0.279 \\
\hline \multicolumn{5}{|l|}{ Admission method } \\
\hline Voluntary & $1(2.1)$ & $15(29.4)$ & 13.328 & $<0.001$ \\
\hline Involuntary & $46(97.9)$ & $36(70.6)$ & & \\
\hline
\end{tabular}

Values are presented as mean \pm standard deviation or number (\%). $t=t$-test; $\chi^{2}=$ chi-square test.

psychotic polypharmacy, and year of institutionalization) were inserted into the second logistic regression analysis. The Hosmer-Lemeshow goodness-of-fit test was used to assess the overall fit of the logistic regression model. All tests were two-tailed. Statistical analyses were carried out using the PASW Statistics software, ver. 18.0 (IBM Co., Armonk, NY, USA), and differences of $p<0.05$ were considered significant.

\section{RESULTS}

\section{Subjects}

For this study, 47 and 52 newly treated patients with schizophrenia were enrolled in 2005 and 2010, respectively. Patient demographic and clinical characteristics are shown in Table 1. There were no differences in the 2005 and 2010 patient groups in terms of sex, age, educational level, socioeconomic status, diagnostic subtype of schizophrenia, or length of hospital stay. The rate of involuntary admissions decreased from $97.9 \%$ in 2005 to $70.6 \%$ in $2010\left(\chi^{2}=13.328 ; p<0.001\right)$.

\section{First-prescribed Antipsychotic Medication}

Fig. 1 shows the first antipsychotic drug obtained from the pharmacy after schizophrenia diagnosis. In 2005, the four most common first-prescribed antipsychotics were olanzapine $(34.0 \%)$, risperidone $(34.0 \%)$, aripiprazole (23.0\%), and haloperidol (19.1\%). In 2009, a new atypical

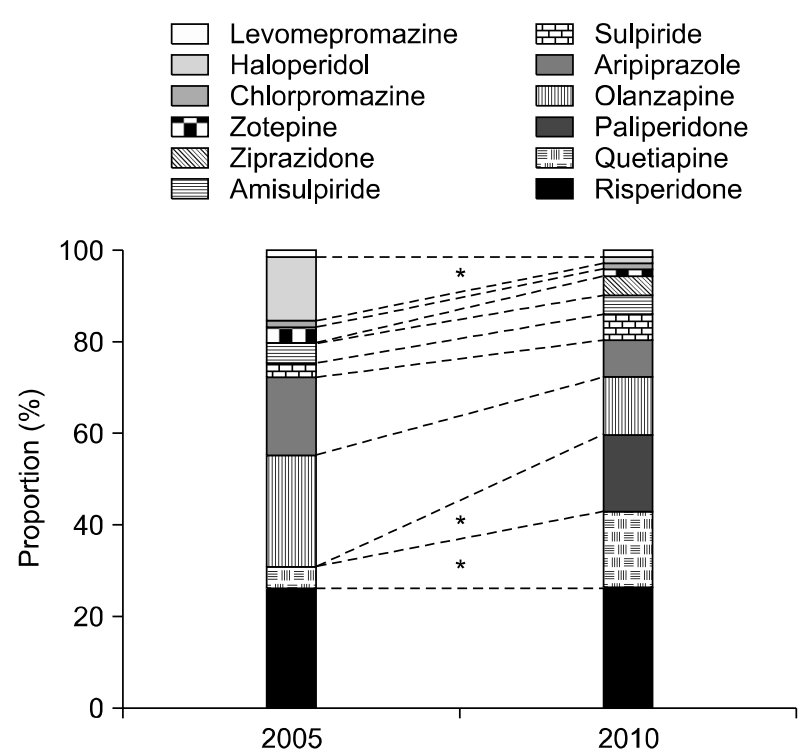

Fig. 1. Proportion of the antipsychotic drug first prescribed after initial schizophrenia diagnosis in 2005 and $2010\left({ }^{*} p<0.05\right)$.

antipsychotic drug, "paliperidone," was introduced after KFDA approval for the treatment of schizophrenia. In 2010, the list of commonly prescribed antipsychotics changed to risperidone (36.5\%), quetiapine $(23.1 \%)$, paliperidone $(23.1 \%)$, and olanzapine $(17.3 \%)$. There were no significant changes in the prescription of FGAs (levomepromazine, chlorpromazine), zotepine, risperidone, olanzapine, clozapine, and amisulpride from 2005 to 2010 
Table 2. Distribution of psychotropic drugs use in patients diagnosed in 2005 and 2010

\begin{tabular}{|c|c|c|c|c|}
\hline Treatment & $2005(n=47)$ & $2010(n=52)$ & $\chi^{2}$ & $p$ value* \\
\hline High dose of antipsychotics & $29(61.7)$ & $28(53.8)$ & 0.624 & 0.430 \\
\hline Antipsychotic polypharmacy & $16(34.0)$ & $18(34.6)$ & 0.004 & 0.952 \\
\hline 1st generation antipsychotics & $12(25.5)$ & $7(13.5)$ & 2.319 & 0.128 \\
\hline 2nd generation antipsychotics & $46(97.9)$ & $52(100)$ & - & $0.475^{\dagger}$ \\
\hline Anticholinergics & $25(53.2)$ & $27(51.9)$ & 0.016 & 0.900 \\
\hline Antidepressants & $3(6.4)$ & $4(7.7)$ & - & $0.800^{\dagger}$ \\
\hline Benzodiazepines & $30(63.8)$ & $27(51.9)$ & 2.564 & 0.278 \\
\hline Mood stabilizers & $0(0.0)$ & $9(17.3)$ & - & $0.003^{\dagger}$ \\
\hline
\end{tabular}

Values are presented as number (\%)

${ }^{*} p$ value on the basis of chi-square test $\left(\chi^{2}\right)$ or ${ }^{\dagger}$ Fisher's exact test.

Table 3. Factors associated with high-dose antipsychotic prescription (combined data from 2005 and 2010)

\begin{tabular}{lccc}
\multicolumn{1}{c}{ Factors } & p value & $\begin{array}{c}\text { Odds } \\
\text { ratio }\end{array}$ & $\begin{array}{c}95 \% \text { confidence } \\
\text { interval }\end{array}$ \\
\hline Young age $(<35 \mathrm{yr})$ & 0.335 & 1.766 & $0.556-5.608$ \\
Sex (male) & 0.321 & 1.840 & $0.552-6.133$ \\
Low socioeconomic status & 0.326 & 2.071 & $0.484-8.865$ \\
Mood stabilizer use & 0.817 & 1.306 & $0.136-12.552$ \\
Number of typical & 0.656 & 1.777 & $0.142-22.251$ \\
$\quad$ antipsychotics use & & & \\
Antipsychotic polypharmacy & 0.008 & 23.965 & $2.313-248.332$ \\
Year of institutionalization (2005) & 0.875 & 1.102 & $0.329-3.695$ \\
\hline
\end{tabular}

(Fig. 1). However, the rate of haloperidol prescription decreased from $19.1 \%$ in 2005 to $1.9 \%$ in 2010 (Fisher's exact test; $p=0.006$ ), and the rate of quetiapine prescription increased from $6.2 \%$ in 2005 to $27.4 \%$ in $2010\left(\chi^{2}=\right.$ $31.434 ; p<0.001)$.

\section{Prescription of Psychotropic Medications}

The practice of antipsychotic polypharmacy and high dose of antipsychotics was similar in 2005 and 2010. A total of $61.7 \%$ and $53.8 \%$ patients were prescribed high doses of antipsychotics in 2005 and 2010, respectively (Table 2), and $34.6 \%$ and $34.0 \%$ of patients were prescribed with antipsychotic polypharmacy in 2005 and 2010 , respectively. The most frequently prescribed drug within the antipsychotics combinations changed from haloperidol in 2005 (50.0\%) to quetiapine in $2010(50.0 \%)$. Prescription of FGAs and SGAs were not significantly different between these years. Prescription of anticholinergics, antidepressants, and benzodiazepines was unchanged between 2005 and 2010; however, prescription of mood stabilizers increased from $0.0 \%$ in 2005 to $17.3 \%$ in 2010 (Fisher's exact test; $p=0.003$ ).

\section{Factors Associated with High Doses of Antipsychotics}

Prescription of high-dose antipsychotics was not asso- ciated with patient age, sex, socioeconomic status, mood stabilizer use, typical antipsychotics use, or year of institutionalization (Table 3). Antipsychotic polypharmacy was most strongly associated with high doses of antipsychotics (odds ratio $=23.965 ; 95 \%$ confidence interval 2.313-248.332; $p=0.008$ ). According to the HosmerLemeshow goodness-of-fit statistics, the reliability of the model was adequate ( $\left.\chi^{2}=3.645 ; p=0.373\right)$.

\section{DISCUSSION}

The purpose of this study was to describe prescription trends for antipsychotics use and related drugs in patients with first-episode schizophrenia by comparing prescribed medications between the years of 2005 and 2010. In the present study, the overall rate of high-dose antipsychotic prescription during the initial inpatient treatment of first-episode schizophrenia was more than $60 \%$ in 2005 and was similarly high in 2010 . Furthermore, both time points showed antipsychotic polypharmacy rates of more than $34 \%$, and polypharmacy was strongly associated with high-dose prescriptions after controlling for other clinical variables.

Many reasons may explain the intensified treatments of high-dose antipsychotics in addition to antipsychotic polypharmacy, despite little scientific evidence to support these treatments. Increasing the dosage and combining different antipsychotics is one of several options that may be chosen when the response to initial prescriptions is insufficient, and high-dose prescriptions may initially be applied if assuming an accelerated response. Furthermore, psychiatrists may begin to prescribe higher doses of SGAs even for initial treatment in first-episode psychosis due to experiences with SGAs causing less-pronounced dosedependent EPS. ${ }^{21)}$

Although no high-quality scientific evidence proves that high-dose therapy is beneficial, ${ }^{22-24)}$ higher doses of 
SGAs may be justified in certain cases, as they may improve psychotic symptoms and optimize $\mathrm{D}_{2}$ receptor blockade if they are titrated close to the peak of their daily dose range. ${ }^{25)}$ A recent study $^{26)}$ shows that high-dose SGAs modestly enhance treatment response and should be considered a viable treatment option for first-episode schizophrenia patients. This may contribute to the use of higher doses overall, particularly in individuals who have been prescribed multiple SGAs. However, the titration of antipsychotic doses should be carefully considered based on relevant clinical characteristics of individual patients due to the uncertain consequences of high-dose therapy.

Our findings suggest that SGAs $(97.9 \%$ in 2005 and $100 \%$ in 2010) have rapidly displaced the older first-generation neuroleptics in the initial treatment of schizophrenia in Korea more so than in other countries. ${ }^{21,27,28)}$ According to a recent comprehensive meta-analysis, ${ }^{29)}$ several SGAs were shown to have a significantly lower treatment discontinuation than FGAs in first-episode schizophrenia patients irrespective of cause, negative symptoms, and global cognition, despite SGAs causing more weight gain. Although SGAs are preferred in treatment recommendations, convincing evidence of an efficacy difference between FGAs and SGAs in treating a first episode of psychosis is still lacking. ${ }^{30)}$ While most studies are post hoc, SGAs studies are often industry-sponsored and tend to have a subtle bias against FGAs in total symptom reduction and response rate. ${ }^{29)}$ According to an update by the National Institute for Health and Clinical Excellence, treatment guidelines are beginning to move away from previous recommendations of SGAs as the first-line drugs in patients with first-episode psychosis. ${ }^{31)}$ Thus, the choice of antipsychotic drug in new-onset schizophrenia treatment may be influenced more by the drug's side-effect profile than its efficacy. ${ }^{32)}$

In the present study, olanzapine was the most commonly prescribed initial antipsychotic medication in 2005, yet it was only the fourth most common in 2010 . This change in prescribing pattern may reflect increasing concerns about weight gain and metabolic disturbances, which are the most frequent and harmful long-term side effects of SGAs. ${ }^{33)}$ Although no data has associated metabolic harm with first-response medication in young schizophrenic patients, all other SGAs except for clozapine are likely less harmful than olanzapine. ${ }^{34,35)}$ The recently updated Schizophrenia Patient Outcomes Research Team (PORT) guidelines recommended specifically against using olanzapine (or clozapine) as a first-line treatment for first-episode psychosis due to its substantial contribution to weight gain and metabolic abnormalities. ${ }^{36)}$

Our data showed that the most frequently prescribed drug within antipsychotic combinations changed from haloperidol in $2005(50.0 \%)$ to quetiapine in 2010 (50.0\%). This finding is consistent with the recent trend of quetiapine as the most frequently co-prescribed drug. ${ }^{21,37,38)}$ Furthermore, $78.8 \%$ of quetiapine prescriptions in combination with other antipsychotics were at doses of lower than $300 \mathrm{mg} /$ day. This may indicate in part that the drug's compounds were often used in conjunction with other antipsychotics as a potent sedative, ${ }^{39)}$ rather than its antipsychotic properties. However, a recent meta-analysis warns that patients with schizophrenia are particularly sensitive to quetiapine-induced metabolic abnormalities, even at low doses. ${ }^{40)}$ Therefore, a prudent approach to prescription and careful monitoring of metabolic side effects is needed when using this antipsychotic to manage first-episode schizophrenia.

The introduction of new compounds for treating psychoses may affect the choice of the first antipsychotic drug after being diagnosed with schizophrenia. In our findings, paliperidone, an atypical antipsychotic medication that was newly approved in 2009, was the second most frequently prescribed drug in 2010. Similarly, the use of aripiprazole, which had been commercialized in Korea after KFDA approval in 2004, was high in 2005 (23\%, third most commonly used drug) and decreased to $11.5 \%$ in 2010. Whereas the prescribing rate of olanzapine decreased substantially over a 5-year period, the use of risperidone was not strongly influenced by the introduction of new antipsychotics and remained relatively steady. Consistent with our findings, olanzapine use decreased and risperidone use remained steady in a 10-year cohort study of newly diagnosed patients with schizophrenia as newly developed antipsychotics were introduced. ${ }^{21)}$ Intensive marketing of new antipsychotics by the pharmaceutical companies may have influenced the observed prescription rate trends, ${ }^{41)}$ and physicians may be more likely to try something new in hopes of maximizing outcomes.

Clozapine has been shown to have advantages over other antipsychotics in terms of efficacy ${ }^{42)}$ and effectiveness ${ }^{43)}$, with comparable cost-effectiveness to that accepted for many medical interventions. ${ }^{44)}$ However, in spite of the clinical guidelines, clozapine is used less and later than recommended, as shown in our findings. Moreover, recent studies ${ }^{4546)}$ indicate that the incidence and mortality of clozapine-induced agranulocytosis, the most feared side effect, could be lower than previously estimated. Another 
cohort study ${ }^{47)}$ reported that all-cause mortality due to clozapine is substantially inferior to that associated with other antipsychotic drugs and recommended that the restrictions regarding the use of the drug be reevaluated. Although few studies have been carried out, randomized clinical trials with clozapine in treating first psychotic episodes have supported the superiority of clozapine over other antipsychotics. ${ }^{48,49)}$ Therefore, clozapine should be considered when choosing antipsychotics for the early treatment of first-episode schizophrenic patients, especially in cases of non-response. ${ }^{50)}$

Although our data came from patients with non-affective and first-episode schizophrenia, we found a significant increase in the prescription of mood stabilizers from 2005 to 2010, which is consistent with the increase in the prescription of mood stabilizers in other studies of first-episode psychosis. ${ }^{21,28)}$ The increased use of mood stabilizers may be due to evidence implicating mood disturbances in the disease burden and prognosis of schizophrenic patients. ${ }^{51)}$ The mood stabilizers may be used in conjunction with antipsychotics to control agitation and violence in the acute psychotic state. ${ }^{52)}$ This intensified conjunctive therapy may be partly attributable to secular trends in the structure and delivery of psychiatric services (i.e., the general shift to voluntary psychiatric hospitalization or outpatient care). The revised mental health legislation in Korea that took effect on March 22, 2009 limits involuntary admission through more stringent admission procedures, which may have influenced the significant decrease in the involuntary admission rate we observed between 2005 and 2010. Under voluntary admission, rapid tranquilization may be required using more active psychopharmacological approaches.

Several limitations of our study warrant consideration. First, although data were collected prospectively as part of the principal investigator's regular clinical duties, our investigation was limited to a retrospective review methodology. Second, we lacked information regarding illness severity and drug tolerability. Third, we performed our investigation at only a single residency-affiliated inpatient facility that carried more acute unstable patients with higher rates of involuntary admission, which may have biased the results toward higher-than-normal rates of high-dose prescriptions. Additionally, the small sample size of this study limits the generalizability of our findings. Finally, our observed rate of high-dose antipsychotic prescription could be somewhat overestimated. DDD, defined as the assumed average dose per day for maintenance treatment, ${ }^{19)}$ has been criticized for promot- ing subtherapeutic doses in the treatment of psychosis. ${ }^{53)}$ Therefore, PDD/DDD ratios may be higher for stabilized patients immediately after hospital discharge than for outpatients during the maintenance phase.

The prescription of high-dose antipsychotics with antipsychotic polypharmacy is a common clinical practice for treating patients with chronic schizophrenia. This study investigating the initial treatment of first-episode schizophrenia showed that the rates of excessive dosing were high in both 2005 and 2010, as more than one-third of patients received two or more antipsychotic agents in both years and antipsychotic polypharmacy was the main factor associated with high-dose antipsychotics use. However, the most common types of antipsychotics prescribed were different between the two years, and the use of mood stabilizers significantly increased for non-affective schizophrenia in 2010. Further prospective studies are needed to determine the optimal dosages of antipsychotics and the effects of concomitant medications during the early stage of psychosis.

\section{- Acknowledgments}

The authors would like to thank all of the staff at Severance Mental Health Hospital for their assistance with this research.

\section{REFERENCES}

1. Malaspina D. Schizophrenia: a neurodevelopmental or a neurodegenerative disorder. J Clin Psychiatry 2006;67:e07.

2. Knapp M, Mangalore R, Simon J. The global costs of schizophrenia. Schizophr Bull 2004;30:279-293.

3. Byrne P. Managing the acute psychotic episode. BMJ 2007;334:686-692.

4. Lieberman JA, Koreen AR, Chakos M, Sheitman B, Woerner M, Alvir JM, et al. Factors influencing treatment response and outcome of first-episode schizophrenia: implications for understanding the pathophysiology of schizophrenia. J Clin Psychiatry 1996;57 Suppl 9:5-9.

5. Huber CG, Naber D, Lambert M. Incomplete remission and treatment resistance in first-episode psychosis: definition, prevalence and predictors. Expert Opin Pharmacother 2008;9:2027-2038.

6. Webb T, Tandon R. Antipsychotic treatment of first-episode or early-onset schizophrenia. Curr Psychiatry Rep 2009;11: 261-263.

7. Moore TA, Buchanan RW, Buckley PF, Chiles JA, Conley RR, Crismon ML, et al. The Texas Medication Algorithm Project antipsychotic algorithm for schizophrenia: 2006 update. J Clin Psychiatry 2007;68:1751-1762.

8. Falkai P, Wobrock T, Lieberman J, Glenthoj B, Gattaz WF, Möller HJ; WFSBP Task Force on Treatment Guidelines for Schizophrenia. World Federation of Societies of Biological Psychiatry (WFSBP) guidelines for biological treatment of schizophrenia, Part 1: acute treatment of schizophrenia. World J Biol Psychiatry 2005;6:132-191.

9. Lehman AF, Lieberman JA, Dixon LB, McGlashan TH, 
Miller AL, Perkins DO, et al; American Psychiatric Association; Steering Committee on Practice Guidelines. Practice guideline for the treatment of patients with schizophrenia, second edition. Am J Psychiatry 2004;161(2 Suppl):1-56.

10. Yang M, Barner JC, Lawson KA, Rascati KL, Wilson JP, Crismon ML, et al. Antipsychotic medication utilization trends among Texas veterans: 1997-2002. Ann Pharmacother 2008; 42:1229-1238.

11. Gallego JA, Bonetti J, Zhang J, Kane JM, Correll CU. Prevalence and correlates of antipsychotic polypharmacy: a systematic review and meta-regression of global and regional trends from the 1970s to 2009. Schizophr Res 2012;138:18-28.

12. Barnes TR; Schizophrenia Consensus Group of British Association for Psychopharmacology. Evidence-based guidelines for the pharmacological treatment of schizophrenia: recommendations from the British Association for Psychopharmacology. J Psychopharmacol 2011;25:567-620.

13. Salimi K, Jarskog LF, Lieberman JA. Antipsychotic drugs for first-episode schizophrenia: a comparative review. CNS Drugs 2009;23:837-855.

14. Barbui C, Biancosino $\mathrm{B}$, Esposito $\mathrm{E}$, Marmai L, Donà $\mathrm{S}$, Grassi L. Factors associated with antipsychotic dosing in psychiatric inpatients: a prospective study. Int Clin Psychopharmacol 2007;22:221-225.

15. Sernyak MJ, Rosenheck R. Clinicians' reasons for deviations from recommended dosing practices for antipsychotic medications. Adm Policy Ment Health 2007;34:540-547.

16. Procyshyn RM, Honer WG, Wu TK, Ko RW, McIsaac SA, Young AH, et al. Persistent antipsychotic polypharmacy and excessive dosing in the community psychiatric treatment setting: a review of medication profiles in 435 Canadian outpatients. J Clin Psychiatry 2010;71:566-573.

17. Barbui C, Nosè M, Mazzi MA, Thornicroft G, Schene A, Becker $\mathrm{T}$, et al. Persistence with polypharmacy and excessive dosing in patients with schizophrenia treated in four European countries. Int Clin Psychopharmacol 2006;21:355-362.

18. American Psychiatric Association. Diagnostic and statistical manual of mental disorders: DSM-IV. 4th ed. Washington, DC:American Psychiatric Association; 1994.

19. WHO Collaborating Centre for Drug Statistics Methodology. Guidelines for ATC classification and DDD assignment. 5th ed. Oslo:WHO Collaborating Centre for Drug Statistics Methodology;2002.

20. Royal College of Psychiatrists. Consensus statement on high dose antipsychotic medication (Council Report CR138). London:Royal College of Psychiatrists;2006.

21. Nielsen J, le Quach P, Emborg C, Foldager L, Correll CU. 10-year trends in the treatment and outcomes of patients with first-episode schizophrenia. Acta Psychiatr Scand 2010;122:356-366.

22. Leucht S, Heres S, Kissling W, Davis JM. Evidence-based pharmacotherapy of schizophrenia. Int $J$ Neuropsychopharmacol 2011;14:269-284.

23. Kinon BJ, Volavka J, Stauffer V, Edwards SE, Liu-Seifert $\mathrm{H}$, Chen L, et al. Standard and higher dose of olanzapine in patients with schizophrenia or schizoaffective disorder: a randomized, double-blind, fixed-dose study. J Clin Psychopharmacol 2008:28:392-400

24. Takahashi H, Yoshida K, Ishigooka J, Higuchi H. Switching to risperidone after unsuccessful treatment of olanzapine in the first-episode schizophrenia: an open trial. Prog Neuropsychopharmacol Biol Psychiatry 2006;30:1067-1072.
25. Schwartz TL, Stahl SM. Treatment strategies for dosing the second generation antipsychotics. CNS Neurosci Ther 2011:17:110-117

26. Agid O, Schulze L, Arenovich T, Sajeev G, McDonald K, Foussias G, et al. Antipsychotic response in first-episode schizophrenia: efficacy of high doses and switching. Eur Neuropsychopharmacol 2013;23:1017-1022.

27. Lass J, Männik A, Bell JS. Pharmacotherapy of first episode psychosis in Estonia: comparison with national and international treatment guidelines. J Clin Pharm Ther 2008;33: 165-173.

28. Wu CS, Lin YJ, Feng J. Trends in treatment of newly treated schizophrenia-spectrum disorder patients in Taiwan from 1999 to 2006. Pharmacoepidemiol Drug Saf 2012;21:989996.

29. Zhang JP, Gallego JA, Robinson DG, Malhotra AK, Kane JM, Correll CU. Efficacy and safety of individual secondgeneration vs. first-generation antipsychotics in first-episode psychosis: a systematic review and meta-analysis. Int $J$ Neuropsychopharmacol 2013;16:1205-1218.

30. Freudenreich O, McEvoy JP. Optimizing outcome with antipsychotic treatment in first-episode schizophrenia: balancing efficacy and side effects. Clin Schizophr Relat Psychoses 2012;6:115-121.

31. National Institute for Clinical Excellence. Schizophrenia: core interventions in the treatment and management of schizophrenia in primary and secondary care. NICE Clinical guideline 82. London:National Institute for Clinical Excellence; 2009.

32. Crossley NA, Constante M, McGuire P, Power P. Efficacy of atypical v. typical antipsychotics in the treatment of early psychosis: meta-analysis. Br J Psychiatry 2010;196:434-439.

33. Abdel-Baki A, Ouellet-Plamondon C, Malla A. Pharmacotherapy challenges in patients with first-episode psychosis. J Affect Disord 2012;138 Suppl:S3-S14.

34. Newcomer JW. Metabolic considerations in the use of antipsychotic medications: a review of recent evidence. $J$ Clin Psychiatry 2007;68 Suppl 1:20-27.

35. Rummel-Kluge C, Komossa K, Schwarz S, Hunger H, Schmid F, Lobos CA, et al. Head-to-head comparisons of metabolic side effects of second generation antipsychotics in the treatment of schizophrenia: a systematic review and meta-analysis. Schizophr Res 2010;123:225-233.

36. Buchanan RW, Kreyenbuhl J, Kelly DL, Noel JM, Boggs DL, Fischer BA, et al; Schizophrenia Patient Outcomes Research Team (PORT). The 2009 schizophrenia PORT psychopharmacological treatment recommendations and summary statements. Schizophr Bull 2010;36:71-93.

37. Correll CU, Shaikh L, Gallego JA, Nachbar J, Olshanskiy V, Kishimoto T, et al. Antipsychotic polypharmacy: a survey study of prescriber attitudes, knowledge and behavior. Schizophr Res 2011;131:58-62.

38. López de Torre A, Lertxundi U, Hernández R, Medrano J. Antipsychotic polypharmacy: a needle in a haystack? Gen Hosp Psychiatry 2012;34:423-432.

39. Gugger JJ, Cassagnol M. Low-dose quetiapine is not a benign sedative-hypnotic agent. Am J Addict 2008;17:454-455.

40. Zhornitsky S, Potvin S, Moteshafi H, Dubreucq S, Rompré PP, Stip E. Dose-response and comparative efficacy and tolerability of quetiapine across psychiatric disorders: a systematic review of the placebo-controlled monotherapy and add-on trials. Int Clin Psychopharmacol 2011;26:183192.

41. Verdoux H, Bégaud B. Pharmaco-epidemiology: what do (and don't) we know about utilisation and impact of psycho- 
tropic medications in real-life conditions? $\mathrm{Br} J$ Psychiatry 2004; 185:93-94.

42. Leucht S, Komossa K, Rummel-Kluge C, Corves C, Hunger $\mathrm{H}$, Schmid F, et al. A meta-analysis of head-to-head comparisons of second-generation antipsychotics in the treatment of schizophrenia. Am J Psychiatry 2009;166:152-163.

43. Tandon R, Belmaker RH, Gattaz WF, Lopez-Ibor JJ Jr, Okasha A, Singh B, et al; Section of Pharmacopsychiatry, World Psychiatric Association. World Psychiatric Association Pharmacopsychiatry Section statement on comparative effectiveness of antipsychotics in the treatment of schizophrenia. Schizophr Res 2008;100:20-38.

44. Wang PS, Ganz DA, Benner JS, Glynn RJ, Avorn J. Should clozapine continue to be restricted to third-line status for schizophrenia?: a decision-analytic model. J Ment Health Policy Econ 2004;7:77-85.

45. Honigfeld G, Arellano F, Sethi J, Bianchini A, Schein J. Reducing clozapine-related morbidity and mortality: 5 years of experience with the Clozaril National Registry. J Clin Psychiatry 1998;59 Suppl 3:3-7.

46. Munro J, O'Sullivan D, Andrews C, Arana A, Mortimer A, Kerwin R. Active monitoring of 12,760 clozapine recipients in the UK and Ireland. Beyond pharmacovigilance. $\mathrm{Br} J$ Psychiatry 1999;175:576-580.

47. Tiihonen J, Lönnqvist J, Wahlbeck K, Klaukka T, Niskanen $\mathrm{L}$, Tanskanen A, et al. 11-year follow-up of mortality in patients with schizophrenia: a population-based cohort study (FIN11 study). Lancet 2009;374:620-627.

48. Lieberman JA, Phillips M, Gu H, Stroup S, Zhang P, Kong $\mathrm{L}$, et al. Atypical and conventional antipsychotic drugs in treatment-naive first-episode schizophrenia: a 52-week randomized trial of clozapine vs chlorpromazine. Neuropsychopharmacology 2003;28:995-1003.

49. Sanz-Fuentenebro J, Taboada D, Palomo T, Aragües M, Ovejero S, Del Alamo C, et al. Randomized trial of clozapine vs. risperidone in treatment-naïve first-episode schizophrenia: results after one year. Schizophr Res 2013;149:156-161.

50. Schennach R, Riedel M, Musil R, Möller HJ. Treatment response in first-episode schizophrenia. Clin Psychopharmacol Neurosci 2012;10:78-87.

51. Siris SG. Depression in schizophrenia: perspective in the era of "Atypical" antipsychotic agents. Am J Psychiatry 2000;157:1379-1389.

52. Weiden PJ, Scheifler PL, McEvoy JP, Frances A, Ross R. Expert consensus treatment guidelines for schizophrenia: A guide for patients and families. J Clin Psychiatry 1999;60(Suppl 11):73-80.

53. Rijcken CA, Monster TB, Brouwers JR, de Jong-van den Berg LT. Chlorpromazine equivalents versus defined daily doses: how to compare antipsychotic drug doses? J Clin Psychopharmacol 2003;23:657-659. 